\title{
Mothers in Mind: Exploring the Efficacy of a Dyadic Group Parenting Intervention for Women Who Have Experienced Intimate Partner Violence and Their Young Children
}

\author{
Angelique Jenney ${ }^{1,2}$ - Katreena Scott ${ }^{3} \cdot$ Michael Wall $^{4,5}$
}

Accepted: 1 September 2021 / Published online: 16 September 2021

(c) The Author(s) 2021

\begin{abstract}
Identifying and responding to the mental health needs of young children ( $0-4$ years) exposed to intimate partner violence is one of the most pressing issues confronting child mental health and welfare sectors today. Children exposed to IPV (CEIPV) are at an increased risk of experiencing maltreatment, developing emotional and behavioral problems, and experiencing other adversities (Kimball, Journal of Family Violence, 31, 625-637, 2016). Among the range of protective factors that can mitigate against this impact is a strong relationship with, and attachment to, a primary caregiver (Holt, Buckley, \& Whelan, Child Abuse \& Neglect, 32, 797-810, 2008). Despite this, there are few evidenced-based programs which address the unique parenting supports required by women who experience domestic violence, while simultaneously attending to the unique developmental and psycho-social needs of exposed young children (Austin, Shanahan, Barrios, \& Macy, Trauma, Violence and Abuse, 20(4), 498-519, 2019). This article describes the development and preliminary evaluation of Mothers in Mind, a trauma-informed, dyadic, mother-child intervention program designed to meet this need. Analyses of data from 36 motherchild dyads who completed pre- and post-group evaluation find that, after program completion, mothers report greater parenting self-efficacy, healthier parenting, and enhanced psychological well-being. The importance of relational capacity building in mother-child dyads impacted by violence and suggestions for future avenues for research and intervention are explored.
\end{abstract}

Keywords Intimate partner violence $\cdot$ Child exposure to violence $\cdot$ Parenting intervention $\cdot$ Child protection

Experiences of intimate partner violence (IPV) often have severe impacts upon women and their children both individually and relationally, potentially impacting

Angelique Jenney

Angelique.jenney@ucalgary.ca

Extended author information available on the last page of the article 
the ways in which mothers are connecting with and supporting their children through shared experiences of abuse and violence (Herman, 2015; Levendosky et al., 2011). In addition, the effects of childhood exposure to intimate partner violence (CEIPV) have been further examined in several meta-analytical studies, mostly with schoolaged children, which have outlined how these early trauma experiences may severely impact childhood psychological, physiological, relational (e.g., attachment), and behavioral health and development (Kimball, 2016; Kitzmann et al., 2003; Wolfe et al., 2003).

The importance of CEIPV has long been recognized within child protection as a risk factor (Gordon, 1988; Swift, 1995); however, it was not until the 1990s that CEIPV was recognized as form of maltreatment in and of itself (Shipman et al., 1999; Stanley, 1997). This change has led to a substantial shift in the nature of cases reported to child protection and a pressing demand for policy and practice responses from child protection organizations related to CEIPV (Edleson et al., 2006; Edleson, 1999b; Miccio, 1995; Schechter \& Edleson, 1994; Shepard \& Raschick, 1999; Whitney \& Davis, 1999; Wilson, 1998). In response to this increased pressure and referrals from child protection agencies for specialized CEIPV services, several promising interventions for school-aged children have been developed and evaluated (Graham-Bermann, 2000; Graham-Bermann \& Hughes, 2003; Graham-Bermann et al., 2007). However, in many such programs, infants and young children are typically provided childcare services as opposed to specific therapeutic intervention with mothers and their infants together. A recent systematic review of interventions addressing parenting in the context of IPV has found limited empirical research involving populations of very young children (Austin et al., 2019).

The Mothers in Mind ${ }^{\mathrm{TM}}$ (MIM) program was developed due to this lack of specialized IPV services for infants and young children and has been modeled on the premise of attachment and relational theories as well as promising individual parent-child psychotherapy approaches (Lieberman \& Van Horn, 2005). These promising individualized approaches, however, can be both resource intensive for community agencies to implement and may present as intimidating for mothers with a history of trauma, as well as those experiencing child protection involvement. The rationale for the development of this community-based group model evolved from hearing client stories of experiencing a heightened sense of shame and blame after attending parenting programs in which they felt "othered" by their trauma histories, combined with understanding the risk of increased scrutiny of mother-child interaction that mothers under investigation by CPS experience. The group process itself is designed to feel more like a mother-child play group than a targeted intervention, and mothers may more easily interact with their children and each other without the sense of being the sole focus of facilitator attentions. In this way, the MIM programming model provides a dyadic approach within a group environment to support women and their young children in promoting healthy patterns of connection and repairing any potential disconnection that may occur between caregivers and children after experiences of violence and abuse (Sura-Liddell \& Jenney, 2016). Consistent with trauma-informed models of service, the intervention, provided as a mother-child play group, emphasizes mothers' choice, strengths and empowerment, 
and an awareness of the impact of trauma on the experience of parenting, child development, and the parent-child relationship.

As described, MIM was designed to be appropriate for mothers who may be involved with CPS due to experiences of IPV. Therefore, this study explored the potential efficacy of embedding the program directly within CPS practice agencies by having child mental health professionals deliver the program on site in the hopes that in developing this collaborative model of service, mothers and their children might receive both referrals and services more directly and reduce the amount of time identified families spent involved with CPS.

\section{The Impact of CEIPV on Infants and Young Children}

Recent knowledge of the relationship between early adversity, including exposure to IPV, on infant mental health has called attention to this highly vulnerable group (Paolozza et al., 2017). A national study of child protection services in Canada reported that when IPV is identified as a concern, infants are more likely to be the targets of child protection investigations, have higher rates of substantiation of maltreatment, and are more likely to be referred to ongoing child protection services (Black et al., 2008; Filippelli et al., 2017; Trocmé et al., 2010). Research has identified that young children exposed to IPV exhibit symptoms of trauma, such as developmental delay, regressive behaviors, emotional dysregulation, and sensitivity to conflict (Bogat et al., 2006; DeJonghe et al., 2005; Kitzmann et al., 2003; Osofsky, 1995, 1999). Beyond symptoms of trauma, exposure to violence within the home may interfere with normative developmental neuronal processes that are related to emotional development, raising concerns about the impact on brain development (Tsavoussis et al., 2014). CEIPV during early childhood may impact autonomic nervous system functioning by reducing the responsivity of the parasympathetic nervous system, the part of the nervous system that is closely connected to important physiological, psychological, and cognitive regulation and health (Rigterink et al., 2010; Thayer et al., 2009). As a result, these children may be less aware of their emotions and experience challenges with processing and regulating negative affect, impacting their ability to understand the cause of their emotions and their capacity to cope with difficult feelings (Katz et al., 2007). Caregivers play an important role in this process of supporting infants and young children with identifying and regulating difficult emotions and feelings (Calkins \& Hill, 2007). Unfortunately, experiences of IPV often shape interactions between caregivers and their young children (Levendosky \& Graham-Bermann, 2000, 2001; Levendosky et al., 2006).

\section{The Impact of Intimate Partner Violence on an Infant's Caregiving Environment}

A caregiver's experiences of violence, even prior to conception, may impact upon their ability to provide an optimal caregiving environment. For example, IPV has been connected to both pregnancy coercion as well as unplanned pregnancies (Miller 
et al., 2010). In addition, research suggests that IPV during pregnancy is also associated with fetal trauma and a general lack of prenatal care (Bailey, 2010; Ferraro et al., 2017). The presence of both pre- and postnatal experiences of trauma, particularly inter-personal trauma and violence, may also be linked to relational difficulties between caregivers and their children, perhaps due to the caregiver's own psychological vulnerability and experiences with post-traumatic symptoms (Goldstein \& Martin, 2004). The ways in which caregivers are individually impacted by their trauma experiences may increase the potential risk of future neglect or maltreatment of their children (Casanueva \& Martin, 2007; Malone et al., 2010). For example, experiences of maternal trauma have been linked with reduced capacities for sensitivity and responsiveness and the ability to appropriately respond to challenging behaviors (such as separation anxiety and temper tantrums) that are part of healthy child development (Cohen et al., 2008; Schechter et al., 2008, 2011). The reduced capabilities of a mother to respond to her child in a sensitive and supportive manner may negatively disrupt the mother-child relationship, particularly if the behavior is emotionally triggering for her or is perceived to be potentially threatening or harmful (Huth-Bocks et al., 2004; Malone et al., 2010). In addition, mothers presenting with adverse early experiences have a heightened risk of post-natal depression as a result of a "cascade effect" from the accumulation of traumatic experiences (such as child abuse, sexual abuse, and/or domestic violence) over time (Madigan et al., 2017).

Researchers have also found that, although elevations in stress are present in women with experiences of trauma and IPV, parenting capacity between individuals often varies (Letourneau et al., 2007; Nixon et al., 2017a, 2017b). In addition, the provision of a safe environment has been found to improve poor parenting (Edleson et al., 2003). This body of research concludes that attention to the external impacts of abusive partners as well as maternal poverty or homelessness, which may contribute to feelings of stress and the lack of safety, are required to promote optimal caregiving. In the case of social work practice, specifically within child protection, some researchers recommend that providing advocacy and supportive services may do more for children exposed to domestic violence than investigative approaches (Friend et al., 2008; Nixon et al., 2017a, 2017b; Nixon et al., 2017a, 2017b). For example, interventions with survivors of IPV that lower depression and increase maternal sensitivity may also provide benefits for children (Manning et al., 2014; Martinez-Torteya et al., 2009).

\section{Dyadic Intervention Research}

The importance of responsive parenting as a fundamental predictor of well-being in children has been emphasized over several decades (Bakermans-Kranenburg et al., 2005). Within these works, there has been a call to focus on the prevention of impairment from adverse experiences, including IPV, while also promoting the socio-emotional developmental health of the child (MacMillan et al., 2009). Interventions that work with mother-child dyads together are particularly appropriate for facilitating responsive caregiving and supportive interactions that are high 
in warmth, nurturance, and comprehension of infant communication cues (Lieberman \& Van Horn, 2005). Dyadic, parent-child responsivity-based approaches have been demonstrated as effective in randomized control trials (RCT) for interventions with children in at risk circumstances, including infants born prematurely (Patteson \& Barnard, 1990), anxiously attached dyads (Lieberman et al., 1991), infants parented by depressed mothers (Cicchetti et al., 1999; Toth et al., 2006), and maltreated children (Cicchetti et al., 2006). Fewer RCTs have evaluated interventions for mothers who have been victims of IPV and their exposed children; however, one study of 75 preschoolers who had been exposed to IPV found that children who had received parent-child intervention showed fewer emotional and behavioral symptoms than a control group of children of mothers receiving case management and community referrals, with significant intervention group differences in total maternal distress; these treatment effects also persisted in the 6-month follow-up study (Ghosh Ippen et al., 2011; Lieberman et al., , 2005, 2006). This study, like many in the field, excluded mothers who were still living with their partners. Recognizing the reality of continued contact between mothers and fathers, Lieberman launched a pilot evaluation of child-parent psychotherapy that included mothers still living with abusive partners (Lavi et al., 2015). Pre- to post-decrease in symptoms of maternal depression and PTSD were found, as well as an increase in positive childrearing attitudes (Lavi et al., 2015). Given the general support for mother-child psychotherapy and the promising results of studies with populations of CEIPV, interventions that address dyadic parent-child responsivity warrant further evaluation and development (MacMillan et al., 2009; Poole et al., 2008).

\section{The Need for Mothers in Mind}

Mothers in Mind (MIM) is a manualized, 10-week, early-intervention, communitybased program focused on promoting the safety and well-being of vulnerable children under the age of four (Sura-Liddell \& Jenney, 2016). Developed in 2006, this model was first implemented at the Child Development Institute (CDI) in Toronto, Ontario, to specifically provide intervention to mothers involved with child protection services, who (with their children) have experienced IPV or other relational trauma (such as child maltreatment or sexual abuse) that may interfere with their relationship. The MIM model has been based on the concept that all relationships, despite exposure to trauma, may find points of healing and growth. Throughout the 10-week program, the intervention places a focus on two core concepts: connection and disconnection. Building on Tronick's (2017) theory of mutual regulation, and the notion of "serve and return" as proposed by the National Scientific Council on the Developing Child (2012), likening the interactive relationship between caregiver and child as a communication tennis match, the program revolves around strengthening such moments of connection (when things go well) and recognizing and repairing the moments of disconnection (when mother or child attempts to cue [or miscues] the other for a response and does not receive it). The program works towards improving outcomes for young children by (1) providing mothers with access to trauma-informed parenting information while connecting with other mothers who 
have had hurtful experiences in their lives; (2) strengthening mothers' self-care, selfcompassion, and stress management skills in relation to parenting; and (3) supporting the mother-child relationship through enhancing sensitivity and responsiveness to children and strengthening feelings of parenting self-efficacy (Sura-Liddell \& Jenney, 2016). The principles of trauma-informed practice, identified as creating safety; recognizing the impact of trauma in order to minimize re-traumatization; exploring the intergenerational, historical, cultural, and gender factors that influence parenting; focusing on healing through healthy relationships, peer support, and maximizing choice; and attending to strengths for both mother and infant (Elliott et al., 2005; Urquhart \& Jasiura, 2013), are core components of this approach, facilitating both individual and group level safety for mothers and children.

The intervention theory of change (see Table 1) supports the program design in that it is offered as a therapeutic play group, with mothers and children together at all times. Groups are comprised of no more than 6-8 mothers with their children, along with three trained facilitators to promote maximum opportunity for individual attention within the group setting. The first three sessions of MIM are dedicated to building safety among group members, introducing mothers and children to the dyadic format of the group, setting group norms, and shared goals, while also supporting mothers with their own understanding and development of self-care, selfcompassion, and stress management. Neff (2003) has suggested that self-compassion as a psychological state may co-exist with compassion (for others) in a general sense, as both internal and external compassion share the underlying components of kindness, common humanity, and mindfulness. Research on self-compassion has highlighted the therapeutic effects it may have for survivors of IPV through supporting both emotional and psychological health and wellbeing (Tesh et al., 2015).

The remaining seven sessions use a psychoeducational approach to build child development knowledge in order to promote increased understanding around issues such as temperament and difficult child behaviors such as temper tantrums, with the intention to reduce potential feelings of fear or hostility towards the child in these instances. Sessions are dedicated to strengthening the mother-child relationship and connection through developing feelings of parental competence by supporting maternal sensitivity and responsiveness. Central to this work is a strength-based approach focused on building self-efficacy. A well-established literature base has recognized the importance of parental self-efficacy on child outcomes (Coleman \& Karraker, 1998) and recommends that parental self-efficacy be a critical component of all parenting intervention programs (Wittkowski et al., 2016). Moreover, self-efficacy in mothers can have positive psychological impacts on both mother and child, and may appear as a mediator of parenting behaviors, specifically in high-risk families (Weaver et al., 2008). The MIM combination of promoting maternal well-being, mother-child dyadic work, and psychoeducation allows clinicians to support mothers, even during moments of disconnection, within a safe, trauma-informed, and compassionate group setting.

The current study aims to describe the sample of mothers who are accessing the MIM program, as well as their experiences with inter-personal trauma across the lifespan. We present the preliminary program evaluation results from twelve MIM group cycles that were offered within a large child protection organization in 

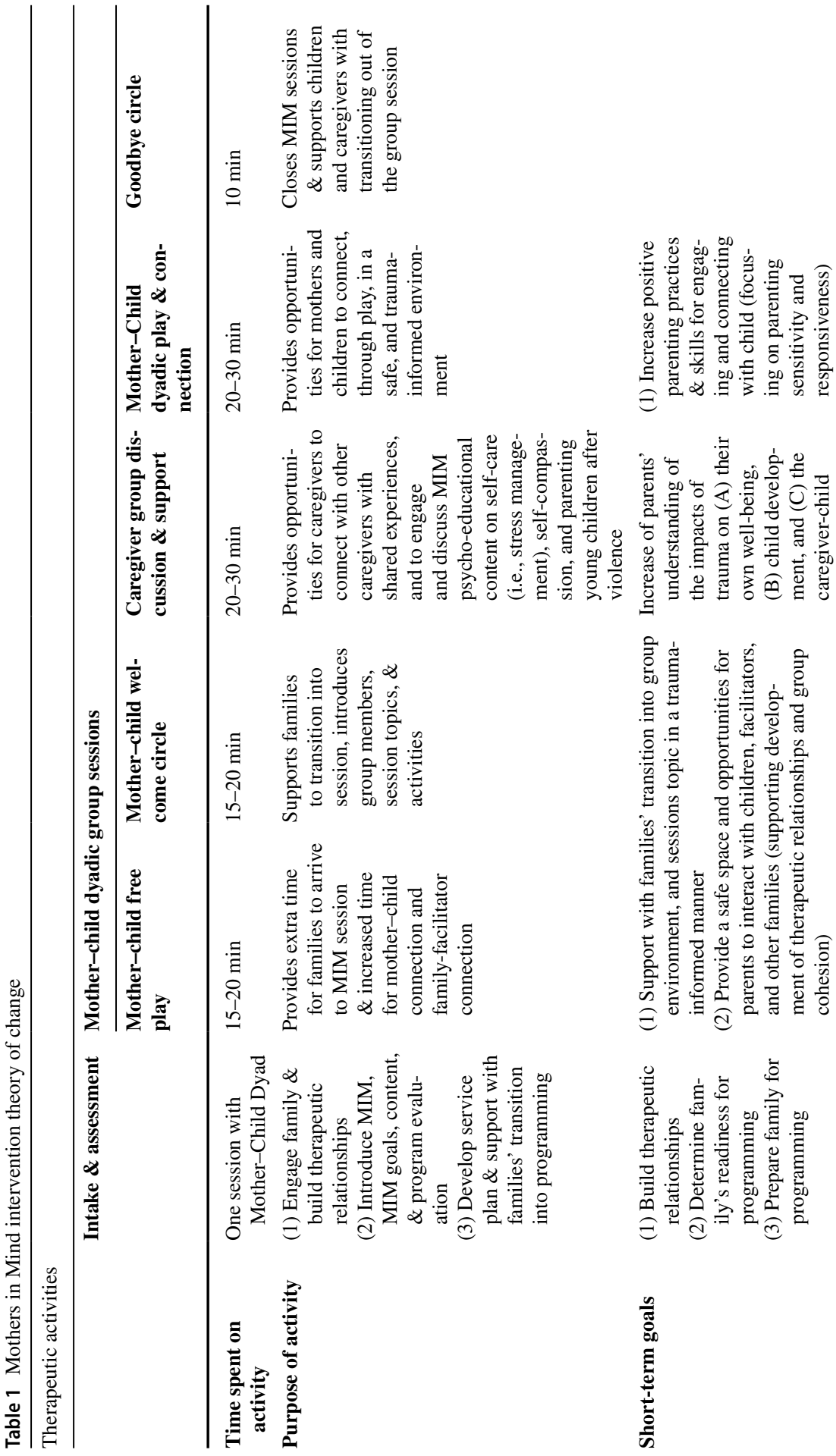

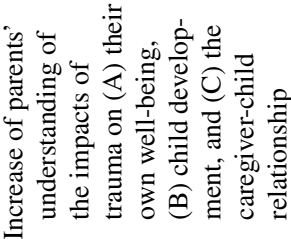

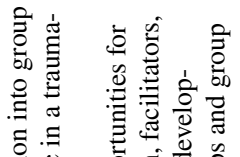
믈

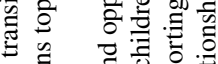

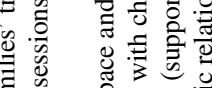
चू

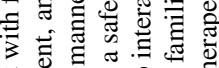

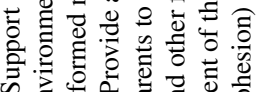

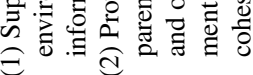

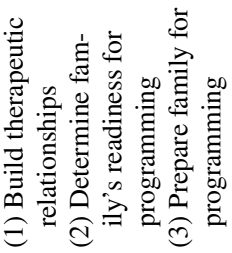
कू 


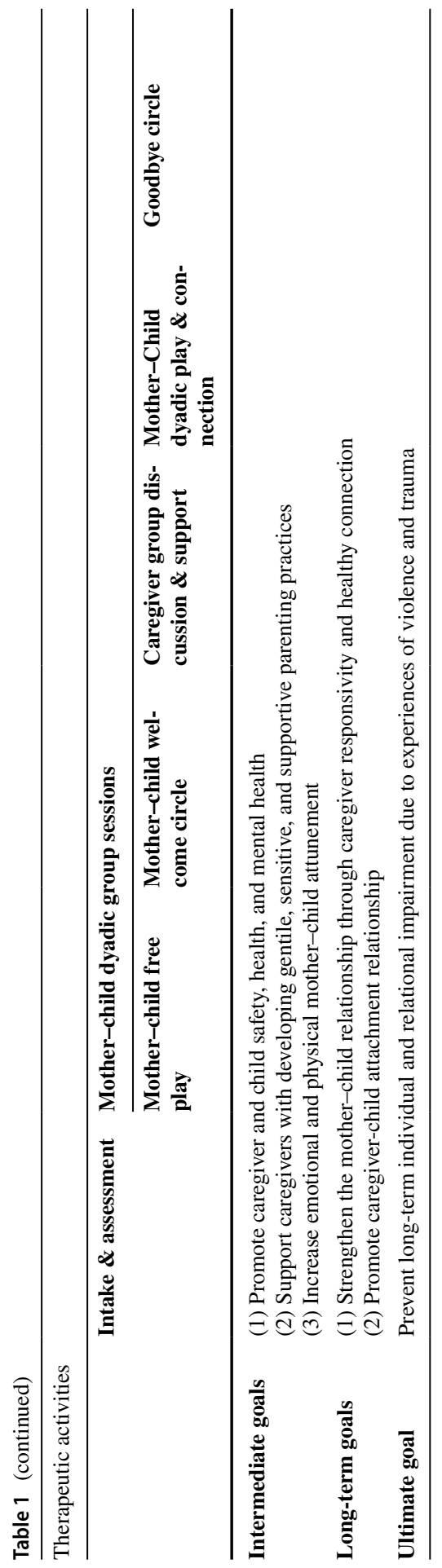


Toronto, Canada. This evaluation focused on how the MIM program supported participants with parenting self-efficacy, knowledge, and behavior. We also examined how the program supported mothers with their own psychological health and wellbeing. Recognizing that additional factors such as maternal mental health may have an impact upon the effectiveness of interventions for abused women (Levendosky et al., 2000; Pinto et al., 2019), we added a measure that screens for symptoms of depression and anxiety within our program evaluation sample. Due to concerns about intrusive or stress-inducing situations for mothers already under the scrutiny of CPS, we chose not to collect data on child well-being which for such young children would entail additional parental reports and observational measures.

\section{Methodology}

\section{Participants and Recruitment}

Participants in this research were drawn from a sample collected as part of the Safe and Understood project, a collaborative research project involving multiple university and community partners which aimed to examine the efficacy of providing collaborative CEIPV intervention services to families of young children who have come to the attention of child protective services. This component of the project focused on families whose child protection cases had not been resolved and closed within a one to 2-month period, but rather had been transferred to "ongoing" child protection services. Thus, children in families involved in this research were those who were deemed most vulnerable to ongoing risk of harm as a result of maltreatment.

Recruitment of families from MIM groups occurred between 2017 and 2019. Mothers were introduced to the MIM program evaluation during the initial stages of the programming intake process. Individuals who were interested in participating were then invited to complete the informed-consent process with a trained research assistant who also supported mothers in the completion of the program evaluation packages during both the first two and last two sessions of the program.

A total of 78 mothers and their children attended the MIM program over this period, with 58 (74\%) expressing an interest in participating in program evaluation. Over the course of the study, six mothers chose not to provide consent to use their data outside of program evaluation purposes, and 16 mothers withdrew from either the program evaluation or the MIM program all together and did not complete the post-group evaluation surveys. A total of 36 mothers (62\% of program evaluation participants; $46 \%$ of program attendees) completed both pre- and post-group evaluation packages and were considered for the final analyses. Program attendance information was collected for 28 of the 36 mothers included in analyses, all of whom attended at least five out of the ten group sessions, with a mean attendance of 8.68 sessions (range between 5 and 10 sessions). The 36 mothers included in the analyses were shown to be statistically comparable to the mothers who did not complete both pre- and post-evaluation packages on all demographic variables with the exception of the mothers' age. Participants who were not included into the analysis due to missing measurement data were shown to be slightly younger than the analysis 
sample, with a mean age of $25(S D=6.5)(t(47)=-2.2, p=0.03)$. The average age of mothers participating in the evaluation was approximately 29 years, with a range of 16 to 42 years. Children attending the MIM groups during the data collection periods ranged in age from infancy ( $0-24$ months) to 4 years of age, with the majority of children (63\%) being within infancy. The 36 participating mothers were of diverse backgrounds with the majority $(61 \%)$ of participants identifying as belonging to a racialized minority group, with approximately $44 \%$ of the sample reporting that they immigrated to Canada from one of ten different countries. As might be expected given the referral pathway to MIM, approximately $19 \%$ of participants reported that their child(ren) had previously lived out of their care for a period ranging from one to 18 months (Table 2).

\section{Measurements}

Demographic Survey Mothers accessing the MIM program and participating in the program evaluation were asked to complete a demographic survey during the preprogram measurement period. The demographic survey was comprised of questions pertaining to the mothers' nationality, ethnicity, educational background, annual income, age (along with the age of their child), and experiences with child protection services. Categorical demographic variables were created within the data to examine the demographic characteristics of mothers accessing the MIM program.

Experiences of Interpersonal Trauma An interpersonal trauma survey created for the purposes of the MIM evaluation was administered during the pre-program

Table 2 Participant demographic characteristics of participating mothers attending program name

\begin{tabular}{|c|c|c|c|}
\hline Demographic variables & Frequency $(\%)$ & Mean (SD) & Range \\
\hline Age of caregiver & & $29(6.5)$ & $16-42$ \\
\hline \multicolumn{4}{|l|}{ Racial/ethnic identity } \\
\hline Caucasian & $12(33)$ & & \\
\hline Black, Caribbean, African-Canadian & $5(14)$ & & \\
\hline Multiracial/ethnic identities & $5(14)$ & & \\
\hline Asian (Eastern \& Southern Asia) & $5(14)$ & & \\
\hline Middle Eastern & $3(8)$ & & \\
\hline Other & $6(16)$ & & \\
\hline Mother born outside of Canada & $16(44)$ & & \\
\hline Number of years living in Canada & & $20(11.5)$ & $2-29$ \\
\hline English as primary language & $23(64)$ & & \\
\hline \multicolumn{4}{|l|}{ Level of education } \\
\hline High school education & $18(50)$ & & \\
\hline Some post-secondary education & $6(17)$ & & \\
\hline Completion of post-secondary education & $9(25)$ & & \\
\hline Children reported to be living out of mothers' care & $7(19)$ & & \\
\hline
\end{tabular}


measurement period. This survey asked participants to self-report experiences of physical abuse, sexual abuse, psychological abuse, and family violence during each major developmental period of their lives (e.g., childhood, adolescence, and adulthood). The survey resulted in twelve binary trauma variables that represented each of the four trauma categories across the three developmental periods. An interpersonal trauma score was created by summing these twelve trauma variables, generating a possible score ranging from zero to twelve for each participant. A score of zero indicated that the individual did not report any abuse or trauma experiences, whereas a score of twelve indicates that the individual had experienced all four categories of abuse during their childhood, adolescence, and adulthood.

Parenting Self-efficacy An adapted version of the Tool of Parenting Self-efficacy (TOPSE; Kendall \& Bloomfield, 2005) was incorporated within the MIM program evaluation to examine the pre- and post-group effect on mothers' perceived parenting self-efficacy. Fourteen of the original 48 TOPSE items were used in the MIM evaluation. Items were chosen based on both theoretical considerations and programming evaluation needs. Two subscales (routines and parental pressures) were deemed inappropriate due to mothers' unique circumstances surrounding child custody (e.g., mothers sometimes did not have full custody of their children and therefore including the subscale pertaining to routines and goals may have been problematic) or because the domain was measured more fully within another area of the MIM evaluation strategy. The remaining 14-item TOPSE contained inter-related items from seven of the original nine domains, including (1) parental affection and emotion; (2) play; (3) empathy and understanding; (4) control; (5) discipline and boundaries; (6) self-acceptance; and (7) parental learning and knowledge. A total score was then generated from these 14 items and used as a measure of parental selfefficacy. The revised instrument was shown to maintain excellent internal reliability (Cronbach's alpha $=0.92$ ).

Parental Knowledge The Raising a Baby (RAB) scale (Kelly et al., 2008) is a 16-item measure of parenting knowledge that captures caregivers' understanding of the socio-emotional needs and developmentally appropriate expectations of their infant and toddler children. For the purposes of the MIM evaluation, a revised 15 -item version of the RAB was administered. One item was removed from the RAB due to its focus on the use of harsh punishments, and the concern that caregivers' responses may be impacted by the presence of child protection services. Items were scored on a 4-point scale and a single total score was calculated and used in analyses. Internal reliability for the RAB measure was found to be within acceptable range (Cronbach's alpha $=0.77$ ).

Parenting Perceptions and Behavior Two subscales of the Parental Cognitions and Conduct Towards the Infant Scale (PACOTIS) were included in the study to examine how MIM impacted (1) mothers' perceived parental impact upon the development of their infant child, and (2) parental hostile-reactive behaviors towards their infant child (Boivin et al., 2005). Caregivers rated each item on an eleven-point scale 
(from 0 to 10) and a mean score for each subscale was calculated for analyses. Internal reliability for the PACOTIS measure was found to be above the acceptable range for both the perceived parental impact (Cronbach's alpha =0.82) and the parental hostile behavior (Cronbach's alpha $=0.89$ ) scales.

Self-compassion The Self-Compassion Scale - Short Form (Raes et al., 2011) was used to examine whether MIM worked towards improving maternal self-compassion for mothers who have experienced IPV and were accessing the program. The short form version of the measure contains 12 items across six subscales that measure an individual's levels of self-kindness, self-judgment, perceived common-humanity, isolation, mindfulness, and the over-identification of distressing thoughts and experiences. The Self-Compassion Short Form was shown to have acceptable internal reliability (Cronbach's alpha $\mathbf{0} 0.76$ ).

Anxiety and Depression The ultra-brief Patient Health Questionnaire-4 (PHQ4) was used in the evaluation to examine mothers' experiences with anxiety and depression symptoms during a 2-week period prior to the evaluation (Löwe et al., 2010). Four items are rated on a four-point scale, ranging from zero ("not at all") to three ("nearly every day"). The total summed score was calculated and used within the analyses to examine pre- and post-group differences. The PHQ-4 was shown to have above acceptable range of internal reliability (Cronbach's alpha $=0.88$ ).

\section{Procedure}

Information about the MIM program evaluation was introduced to clients by program staff during the individual intake sessions, where clients are provided with the opportunities to learn about the program, organization, and program evaluation. By introducing the program evaluation prior to the beginning of group, clients can ask any questions they may have and become familiar with the processes of informed consent and program evaluation. During the first session of the program, each client was invited to participate and to complete individual and group level informed program evaluation and research consents. As MIM is a group-intervention designed for mothers and their infant-to-toddler aged children, children themselves were not recruited to participate within the program evaluation and measures of child wellbeing were not utilized due to perceived additional participant burden. Program evaluation data was collected during the first and last two sessions of the program.

\section{Data Analysis}

Data from participating clients were managed and analyzed using IBM SPSS Statistics 22 (IBM, 2012). Missing values were handled in a conservative manner, by which the patterns and percentiles of missing values for both individuals and the sample were examined (Cheema, 2014). Pairwise deletion was completed for cases that had less than $80 \%$ of measurement data available in either the pre- or post-group measurement periods. Univariate and bivariate analyses 
were conducted on the demographic, trauma, and measurement variables to gain an understanding of the distribution and relationships between demographic and outcome measurements. A series of dependent $t$-tests were employed to examine the changes in parenting and maternal well-being outcomes from the pre- to postgroup measurement periods. Cohen's $d$ was calculated for each outcome variable to examine pre-post effect size change.

\section{Results}

\section{Maternal Experiences with Abuse and Interpersonal Violence}

Participants in the MIM program reported extensive histories of interpersonal trauma and violence victimization at some point throughout their lives (childhood, adolescence, or adulthood). Two participants chose not to complete the interpersonal trauma survey, and thus were not included in analyses using the trauma items, while one other reported no exposure to violence (and thus had a trauma score of zero). Although intake criteria for MIM specifically require mothers to indicate a history of trauma, it may be possible that the location of the evaluation (various CPS locations) had an impact upon some individuals' willingness to self-report previous exposures to violence and abuse. The respondents that completed the questionnaire $(n=34)$ had a mean trauma score of $5.7(S D=3.4)$, with a range of zero to twelve. The vast majority of individuals reported prior experiences of physical abuse (89\%), psychological abuse $(78 \%)$, intimate partner or family violence (64\%), and sexual abuse (52\%) throughout their lifetime. Twenty-eight participants $(77 \%)$ had a trauma score between three and twelve, whereas five participants $(14 \%)$ had a trauma score between one and two. In addition, many participating mothers also reported that they themselves have experienced CEIPV both during their childhood (36\%) and adolescent (46\%) years. Table 3 outlines mothers' reported experiences with interpersonal trauma from childhood to adulthood.

Table 3 Mothers' experiences of interpersonal trauma and violence

\begin{tabular}{lllll}
\hline $\begin{array}{l}\text { Inter-personal trauma } \\
\text { variables }\end{array}$ & $\begin{array}{l}\text { Childhood } \\
\text { frequency } \\
(\%)\end{array}$ & $\begin{array}{l}\text { Adolescence } \\
\text { frequency } \\
(\%)\end{array}$ & $\begin{array}{l}\text { Adulthood } \\
\text { frequency } \\
(\%)\end{array}$ & $\begin{array}{l}\text { Experiences of inter-personal } \\
\text { trauma at any time frequency } \\
(\%)\end{array}$ \\
\hline Physical abuse & $13(36 \%)$ & $12(34 \%)$ & $29(80 \%)$ & $32(89 \%)$ \\
Sexual abuse & $9(25 \%)$ & $8(23 \%)$ & $12(33 \%)$ & $19(52 \%)$ \\
Psychological abuse & $14(39 \%)$ & $14(39 \%)$ & $28(78 \%)$ & $28(78 \%)$ \\
Intimate partner violence & $13(36 \%)$ & $16(46 \%)$ & $17(47 \%)$ & $23(64 \%)$ \\
\hline
\end{tabular}

Note: Categories reported are mutually exclusive. Percentages for each category are calculated from the total sample $(n=36)$ 


\section{Parenting and Maternal Well-being Outcome Measurements}

Bivariate correlations between the continuous measurement scores revealed expected positive correlations between parenting self-efficacy, self-compassion, and hostile reactive behaviors. All program outcome measures were moderately intercorrelated across time. The parenting self-efficacy measure was most consistently associated with other measures, whereas parenting hostility was least often correlated with other measures used in the study (Table 4).

In order to explore the pre- and post-group changes in scores, a series of dependent $t$-test procedures were conducted on each of the outcome variables. It was found that the MIM intervention significantly improved scores of parenting self-efficacy $(t(34)=-2.0, p=0.046, d=0.36)$, parenting knowledge $(t(25)=-2.5, p=0.01$, $d=0.49)$, and maternal self-compassion $(t(30)=-2.2, p=0.035, d=0.33)$, and anxiety and depression $(t(31)=2.1, p=0.040, d=0.27)$. There were no significant pre-post-group results for the parental perceptions or behaviors (PACOTIS) scales (Table 5). Effect sizes for each of the analyses were shown to be small, with a Cohen's $d$ ranging from 0.20 to 0.49 .

\section{Discussion}

Previous research within the area of CEIPV has discussed the ways in which young children's trauma experiences and symptoms may negatively interact with their mothers' experiences and symptoms of trauma, potentially disrupting caregiving behaviors, sensitivity, and the mother-child relationship (Lannert et al., 2014; Levendosky et al., 2011). In addition, Herman (2015) describes the isolating effects that IPV-specific trauma can have upon individuals, which in turn may lead to further relational disconnections. Therefore, the importance of relational connection has been emphasized in previous work as an important mechanism for one's trauma healing and recovery (Herman, 2015). Within the context of parenting, and shared experiences of inter-personal trauma between mothers and their children, this relational connection between parents and children is particularly important in order to further support the child within their own developmental healing and growth. The MIM program fills an important service gap within the area of infant CEIPV, as it strives to promote mothers' sensitivity and responsiveness to their young children's needs through increased knowledge of child development and decreased feelings of fear and hostility towards distressing child behaviors (such as excessive crying and temper tantrums) that may be particularly challenging due to maternal experiences of trauma. The program does this within a group model that also fosters opportunities for reduced social isolation and increased relational connections with mothers and other children. In addition, many parenting programs target adults only, using psychoeducation and scenario examples; however, dyadic interventions may offer more opportunities for supporting the direct implementation of acquired skills. Univariate analysis of the demographic and inter-personal trauma variables indicate that the program is predominately providing support to mothers who have had significant experiences of interpersonal violence and trauma. The sample of mothers included 


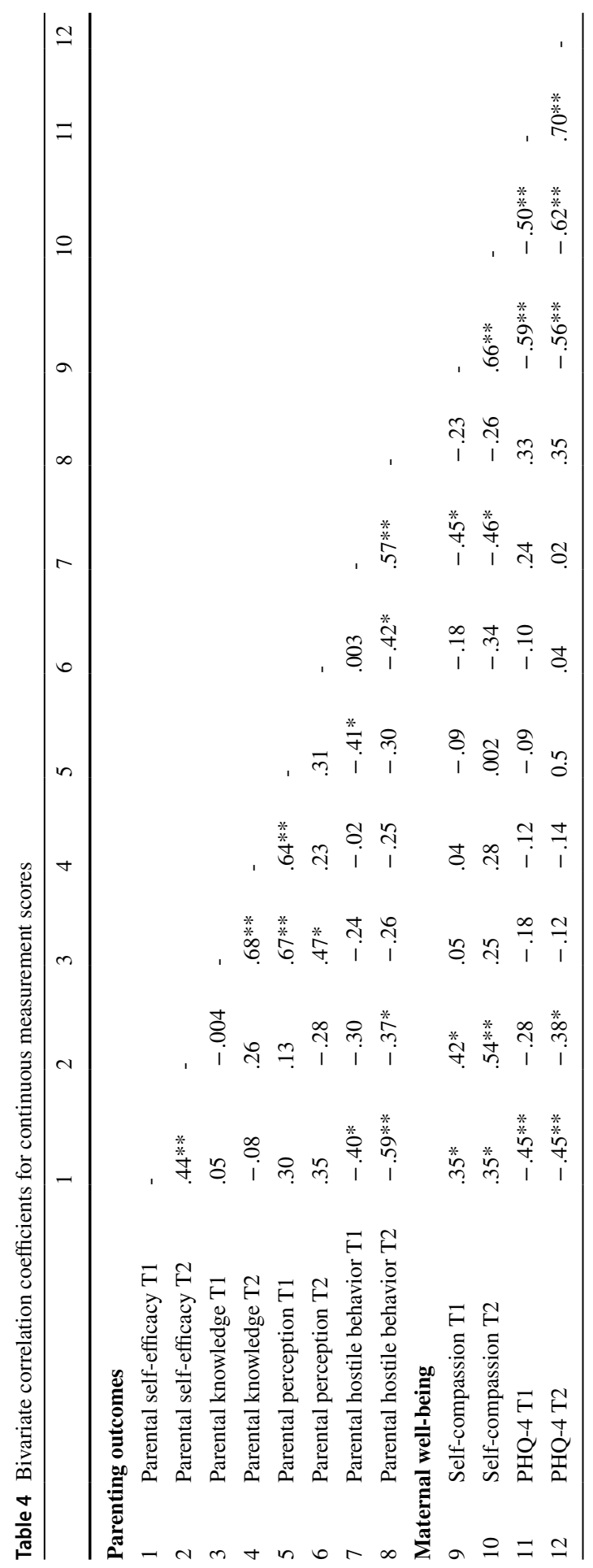


Table 5 Pre- and post-group dependent $t$-test results

\begin{tabular}{|c|c|c|c|c|c|c|c|}
\hline & $n$ & $\begin{array}{l}\text { Pre-group } \\
\dot{x}(S D)\end{array}$ & $\begin{array}{l}\text { Post-group } \\
x^{-}(S D)\end{array}$ & $T$ & $d f$ & p-value & $\begin{array}{l}\text { Effect size } \\
\text { (Cohen's } d \text { ) }\end{array}$ \\
\hline \multicolumn{8}{|l|}{ Parenting outcomes } \\
\hline \multicolumn{8}{|l|}{ Parenting self-efficacy } \\
\hline TOPSE total & 35 & $121(20.8)$ & $129(23)$ & -2.0 & 34 & $.046^{*}$ & 0.36 \\
\hline \multicolumn{8}{|l|}{ Parenting knowledge } \\
\hline RAB total & 26 & $48(7)$ & $51(5)$ & -2.5 & 25 & $.01^{*}$ & 0.49 \\
\hline \multicolumn{8}{|l|}{ Parenting cognitions \& behavior } \\
\hline Perceived parental impact & 28 & $6.2(3.2)$ & $7.0(3)$ & -1.0 & 27 & .287 & 0.26 \\
\hline Parental hostile-reactive behavior & 28 & $3.0(2.9)$ & $2.5(2.1)$ & -1.3 & 27 & .211 & 0.20 \\
\hline \multicolumn{8}{|l|}{ Maternal well-being } \\
\hline \multicolumn{8}{|l|}{ Self-compassion } \\
\hline Self-compassion total score & 31 & $37.6(8.0)$ & $40.6(10)$ & -2.2 & 30 & $.035^{*}$ & 0.33 \\
\hline \multicolumn{8}{|l|}{ Anxiety \& depression } \\
\hline PHQ-4 total score & 32 & $4.0(3.0)$ & $3.0(3.5)$ & 2.1 & 31 & $.040 *$ & 0.27 \\
\hline
\end{tabular}

Note: * Indicates that the difference between pre- and post-scores were statistically significant $(p<.05)$

in the program evaluation reported high levels of such trauma spanning from childhood to adulthood. It is worth considering that future programming might consider a continuum of service that provides adult-centered support around trauma experiences prior to moving into dyadic offerings.

The preliminary evaluation results presented here have indicated that MIM may be supporting mothers on the development of key parenting outcomes, including parenting self-efficacy and parental knowledge. Previous work has shown that parenting self-efficacy is an important construct for parenting behaviors (e.g., responsiveness), and the formation of the parent-child attachment relationship (Jackson, 2000; Weaver et al., 2008). Experiences of trauma (and particularly inter-personal trauma) have the potential to disrupt parenting self-efficacy, and thus may negatively impact parenting behaviors and relationships. The group-based approach to dyadic support through MIM provided mothers with the opportunity to practice connecting (and repairing moments of disconnection) with their children in a safe and supportive environment. Facilitators hold in balance the demands of the group, while also attending to individual dyads and the patterns of connection and disconnection that may be present between mothers and their children. The group-based component of the program allows mothers to provide and receive support from both trained facilitators as well as other mothers who have had similar experiences of inter-personal trauma and relational disconnections.

Mothers in Mind was shown to also benefit maternal health and well-being, as evidenced by the significant pre- and post-group changes on both the self-compassion and patient health questionnaire (a brief assessment tool that screens for anxiety and depression symptoms). Although not specifically designed to address these issues, it seems that involvement in the program provides further benefits to maternal mental health that require additional exploration. Self-compassion has been 
included in the MIM curriculum, as it has been shown to be a promising construct in the healing and recovery process after experiencing inter-personal trauma (Tesh et al., 2015). Self-compassion may also have a positive impact upon parenting and the mother-child relationship for families who have experienced intimate partner violence, as the core components of self-compassion (including self-kindness) may facilitate a shift in perspective towards their own experiences as well as the experiences of their children. For an example, an increase in self-compassion may allow parents to gain additional empathy for their own parenting challenges, as well as any difficulties that their child may be experiencing. The role that self-compassion has within parenting and the MIM program (as a potential mechanism of change) has been validated by the pre- and post-group changes on this measure, as well as the significant positive relationship that was found between the parenting self-efficacy and self-compassion outcome measurements (Table 4). Self-compassion and parenting self-efficacy were also shown to be significantly correlated with anxiety and depression scores. The MIM program and the underlying programming theory of change were not designed to treat anxiety and depression symptoms; however, the patient health questionnaire four (PHQ-4, Löwe et al., 2010) was originally included to examine the level of anxiety and depression symptoms within clients accessing MIM, and to account for the potential negative effects that anxiety and depression may have upon programming effectiveness. Anxiety and depression scores were shown to be negatively associated with parenting self-efficacy scores and self-compassion scores at both time one and time two (Table 4). Although the pre-/post-findings on the PHQ-4 were significantly different, scores were still above the clinical cut-off for anxiety and depression at the post-group period. The small decrease in anxiety and depression scores during the MIM program may be attributed to caregivers' increase of self-compassion and parenting self-efficacy, which may also facilitate a decrease in experiences of stress for caregivers parenting young children after violence. Although these results are promising, more testing is required to fully establish the relationships between caregivers' psychological health and the effects of the MIM program.

Hypothesized program effects were not shown for measures of parental impact or for parental hostile behaviors. Mothers' perceptions of their parental impact upon their child's development were shown to be positively associated with parenting knowledge scores; however, the relationships between parenting self-efficacy and perceived parental impact were trending, but not significant (Table 4) suggesting that this is another area for consideration to determine whether it is an issue of sample size or perhaps the measures themselves are not reliably getting at the area of inquiry. Parenting hostile behavior scores on the other hand were shown to have a negative significant relationship with parenting self-efficacy scores during the pre- and post-group measurement periods. However, pre-group scores on this measure were shown to be much lower than expected, indicating a potential basement effect. This may explain the lack of a pre-/post-change on this measure, as parents' scores during the pre-group period may have been too small to accurately reflect the amount of change created by the intervention. Another important factor to consider is the location and implementation of the MIM program for this project, as groups were held within child protection agencies; this setting may have had an 
impact upon mothers' decision to participate within the evaluation study, or how they responded to some questions within the evaluation, particularly questions pertaining to hostile parenting behaviors. It is interesting to note that despite high rates of withdrawal from the evaluation component of the program, program completion rates remained fairly consistent and client satisfaction feedback positive, suggesting that participants found the evaluation to be burdensome or stressful. The lessons learned from this have supported the development of improved trauma-informed evaluation methodologies for CEIPV community programs and researchers. Working in collaboration with partnered clinical staff and management, the authors have developed a training workshop for students, staff, and researchers that focuses on the integration of important trauma-informed knowledge and practice skills into the evaluation process. This workshop also strives to build more client-centered and strengths-based approaches to evaluation, and places an emphasis upon the importance of collaborative, practice-based evaluation designs in hopes of improving rates of study retention in the future.

\section{Limitations and Future Directions}

It is important to emphasize that our findings and conclusions are limited due to the simplicity of the pre- and post-program evaluation design, along with a smaller than anticipated sample size. Without a randomly assigned comparison sample, it is not possible to make any causal statements about the effect of attending Mothers in Mind. A longstanding clinical practice policy within the family violence service stream of the organization is to not maintain a service waitlist; as for safety reasons, it is extremely important that families have access to family violence services when needed. Therefore, creating a more rigorous evaluation design within MIM can be challenging. There are also still outstanding questions about outcomes for mothers who attended the program but chose not to participate in research. Despite assurances of confidentiality, it is likely that the child protection context in which this program was provided created concerns about scoring poorly on measures related to parenting. Low levels of literacy and high levels of stress may have been additional contributors. In addition, this study did not utilize any measures directly related to child well-being, and therefore, despite the focus on such an intervention as being for the benefit of the children involved, their young voices remain absent from our data set. Continuing to develop accessible, safe, appropriate, non-intrusive forms of measuring outcomes for such young children as well as their mother-child relationships remains an area for further exploration. Despite the noted limitations, this initial evaluation has provided invaluable information surrounding how this groupbased dyadic approach program supports mothers with their parenting and their own health and well-being, a factor which is well-established in the literature as being the key to healthy child development (Phua, Kee, \& Meaney, 2020). It has established preliminary evidence of the effectiveness of MIM within the context of a child protection agency and provided program developers and facilitators a better understanding of how program implementation and delivery may be improved for future programming sessions. 


\section{Conclusion}

MIM is a promising evidence- and trauma-informed program that has been designed to fill a specific service gap within the area of infant CEIPV, that of mother-infant dyadic group work. This program strives to promote maternal sensitivity and responsiveness, while strengthening the mother-child connection and relationship. The preliminary evaluation results presented here have indicated that MIM significantly improves parenting outcomes, including parenting-self-efficacy and knowledge, as well as outcomes pertaining to mothers' psychological health and wellbeing (maternal self-compassion, and anxiety and depression). Both areas have been shown to be important for trauma healing and recovery, as well as developing parenting responsivity and promoting the mother-child relational connection (Jackson, 2000; Weaver et al., 2008). This evaluation is part of a larger project examining the positive effects of supportive services for families experiencing IPV within the context of child protection services. Future findings from this project are expected to further increase our understanding of parenting interventions that aim to promote the health and safety of children and their mothers who have experienced interpersonal trauma and violence.

Funding This research was supported by funds granted by the Public Health Agency of Canada.

\section{Declarations}

Conflict of Interest The authors declare no competing interests.

Open Access This article is licensed under a Creative Commons Attribution 4.0 International License, which permits use, sharing, adaptation, distribution and reproduction in any medium or format, as long as you give appropriate credit to the original author(s) and the source, provide a link to the Creative Commons licence, and indicate if changes were made. The images or other third party material in this article are included in the article's Creative Commons licence, unless indicated otherwise in a credit line to the material. If material is not included in the article's Creative Commons licence and your intended use is not permitted by statutory regulation or exceeds the permitted use, you will need to obtain permission directly from the copyright holder. To view a copy of this licence, visit http://creativecommons.org/licenses/by/4.0/.

\section{References}

Austin, A. E., Shanahan, M. E., Barrios, Y. V., \& Macy, R. J. (2019). A systematic review of interventions for women parenting in the context of intimate partner violence. Trauma, Violence and Abuse, 20(4), 498-519.

Bailey, B. A. (2010). Partner violence during pregnancy: Prevalence, effects, screening and management. International Journal of Women's Health, 2, 183-197.

Bakermans-Kranenburg, M. J., Van Ijzendoorn, M. H., \& Juffer, F. (2005). Disorganized infant attachment and preventive interventions: A review and meta-analysis. Infant Mental Health Journal, 26(3), 191-216.

Black, T., Trocmé, N., Fallon, B., \& MacLaurin, B. (2008). The Canadian child welfare response to investigations involving exposure to domestic violence. Child Abuse \& Neglect, 32, 393-404.

Bogat, G. A., DeJonghe, E. S., Levendosky, A. A., Davidson, W. S., \& von Eye, A. (2006). Trauma symptoms among infants exposed to intimate partner violence. Child Abuse \& Neglect, 30, 109-125. 
Boivin, M., Perusse, D., Dionne, G., Saysset, V., Zoccolillo, M., \& Tarabulsy, G. (2005). Parent's perceptions and self-assessed behaviors toward their 5-month-old infants in a large twin and singleton sample. Journal of Child Psychology and Psychiatry, 46, 612-630.

Calkins, S. D., \& Hill, A. (2007). Caregiver influences on emerging emotion regulation: Biological and environmental transactions in early development. In J. J. Gross (Ed.), Handbook of emotion regulation (pp. 229-248). The Guilford Press.

Casanueva, C. E., \& Martin, S. L. (2007). Intimate partner violence during pregnancy and mothers' child abuse potential. Journal of Interpersonal Violence, 22(5), 603-622.

Cheema, J. R. (2014). A review of missing data handling methods in education research. Review of Educational Research, 84(4), 487-508.

Cicchetti, D., Rogosch, F. A., \& Toth, S. L. (2006). Fostering secure attachment in infants in maltreating families through preventive interventions. Development and Psychopathology, 18(3), 623-649.

Cicchetti, D., Toth, S. L., \& Rogosch, F. A. (1999). The efficacy of toddler-parent psychotherapy to increase attachment security in offspring of depressed mothers. Attachment and Human Development, 1(1), 34-66.

Cohen, L. R., Hien, D. A., \& Batchelder, S. (2008). The impact of cumulative maternal trauma and diagnosis on parenting behavior. Child Maltreatment, 13(1), 27-38.

Coleman, P. K., \& Karraker, K. H. (1998). Self-efficacy and parenting quality: Findings and future applications. Developmental Review, 18, 47-85.

DeJonghe, E. S., Bogat, G. A., Levendosky, A. A., von Eye, A., \& Davidson, W. S. (2005). Infant exposure to domestic violence predicts heightened sensitivity to adult verbal conflict. Infant Mental Health Journal, 26(3), 268-281.

Edleson, J. L. (1999a). Children's witnessing of adult domestic violence. Journal of Interpersonal Violence, 14(8), 839-870.

Edleson, J. L. (1999b). The overlap between child maltreatment and woman battering. Violence against Women, 5(2), 134-154.

Edleson, J. L., Gassman-Pines, J., \& Hill, M. B. (2006). Defining child exposure to domestic violence as neglect: Minnesota's difficult experience. Social Work, 51(2), 167-174.

Edleson, J. L., Mbilinyi, L. F., \& Shetty, S. (2003). Parenting in the context of domestic violence. San Francison, CA: Judicial Council of California.

Elliott, D. E., Bjelajac, P., Fallot, R. D., Markoff, L. S., \& Glover-Reed, B. (2005). Trauma-informed or trauma-denied: Principles and implementation of trauma-informed services. Journal of Community Psychology, 33(4), 461-477.

Ferraro, A. A., Rohde, L. A., Polanczyk, G. V., Argeu, A., Miguel, E. C., Grisi, S. J. F. E., \& FleitlichBilyk, B. (2017). The specific and combined role of domestic violence and mental health disorders during pregnancy on new-born health. BioMedCentral Pregnancy and Childbirth, 17(257), 1-10.

Filippelli, J., Fallon, B., Trocme, N., Fuller-Thomson, E., \& Black, T. (2017). Infants and the decision to provide ongoing child welfare services. Child and Adolescent Psychiatry and Mental Health, 11(24), 1-15. https://doi.org/10.1186/s13034-017-0162-7

Friend, C., Shlonksy, A., \& Lambert, L. (2008). From evolving discourses to new practice approaches in domestic violence and child protective services. Children and Youth Services Review, 30, 689-698.

Ghosh Ippen, C., Harris, W. W., Van Horn, P., \& Lieberman, A. F. (2011). Traumatic and stressful events in early childhood: Can treatment help those at highest risk? Child Abuse \& Neglect, 35, 504-513.

Goldstein, K. M., \& Martin, S. L. (2004). Intimate partner physical assault before and during pregnancy: How does it relate to women's psychological vulnerability? Violence and Victims, 19(4), 387-398.

Gordon, L. (1988). Heroes of their own lives: The politics and history of family violence. New York, NY: Viking.

Graham-Bermann, S. A. (2000). Preschool kids' club: A preventive intervention program for young children exposed to violence. Ann Arbor, MI: Department of Psychology.

Graham-Bermann, S. A., \& Hughes, H. M. (2003). Intervention for children exposed to interparental violence (IPV): Assessment of needs and research priorities. Clinical Child and Family Psychology Review, 6(3), 189-204.

Graham-Bermann, S. A., Lynch, S., Banyard, V., DeVoe, E. R., \& Halabu, H. (2007). Community-based intervention for children exposed to intimate partner violence: An efficacy trial. Journal of Consulting and Clinical Psychology, 75(2), 199-209.

Herman, J. L. (2015). Trauma and recovery: The aftermath of violence - From domestic abuse to political terror. Basic Books. 
Holt, S., Buckley, H., \& Whelan, S. (2008). The impact of exposure to domestic violence on children and young people: A review of the literature. Child Abuse \& Neglect, 32, 797-810.

Huth-Bocks, A. C., Levendosky, A. A., Theran, S. A., \& Bogat, G. A. (2004). The impact of domestic violence on mothers' prenatal representations of their infants. Infant Mental Health Journal, 25(2), 79-98.

IBM. (2012). IBM SPSS Statistics for Windows (Version 21.0). Armonk, NY: IBM Corporation.

Jackson, A. P. (2000). Maternal self-efficacy and children's influence on stress and parenting among single black mothers in poverty. Journal of Family Issues, 21(1), 3-16.

Katz, L. F., Hessler, D. M., \& Annest, A. (2007). Domestic violence, emotional competence, and child adjustment. Social Development, 16(3), 513-538.

Kelly, J. F., Korfmacher, J., \& Buehlman, K. (2008). Ways of being with children (Unpublished manuscript). University of Washington, Seattle, WA.

Kendall, S., \& Bloomfield, L. (2005). Developing and validating a tool to measure parenting self-efficacy. Journal of Advanced Nursing, 51(2), 174-181.

Kimball, E. (2016). Edleson revisited: Reviewing children's witnessing of domestic violence 15 years later. Journal of Family Violence, 31, 625-637.

Kitzmann, K. M., Gaylord, N. K., Holt, A. R., \& Kenny, E. D. (2003). Child witnesses to domestic violence: A meta-analytic review. Journal of Consulting and Clinical Psychology, 71(2), 339-352.

Lannert, B. K., Garcia, A. M., Smagur, K. E., Yalch, M. M., Levendosky, A. A., Bogat, G. A., \& Lonstein, J. S. (2014). Relational trauma in the context of intimate partner violence. Child Abuse \& Neglect, 38(12), 1966-1975.

Lavi, I., Gard, A. M., Hagan, M., Van Horn, P., \& Lieberman, A. F. (2015). Child-parent psychotherapy examined in a perinatal sample: Depression, posttraumatic stress symptoms and child-rearing attitudes. Journal of Social and Clinical Psychology, 34(64). https://doi.org/10.1521/jscp.2015.34.1.64

Letourneau, N. L., Fedick, C. B., \& Willms, J. D. (2007). Mothering and domestic violence: A longitudinal analysis. Journal of Family Violence, 22, 649-659.

Levendosky, A. A., Bogat, G. A., \& Huth-Bocks, A. C. (2011). The influence of domestic violence on the development of the attachment relationship between mother and young child. Psychoanalytic Psychology, 28(4), 512-527.

Levendosky, A. A., \& Graham-Bermann, S. A. (2000). Trauma and parenting in battered women: An addition to an ecological model of parenting. In R. A. Geffner, P. G. Jaffe, \& M. Sudermann (Eds.), Children exposed to domestic violence: Current issues in research, intervention, prevention, and policy development (pp. 25-35). Haworth Press.

Levendosky, A. A., \& Graham-Bermann, S. A. (2001). Parenting in battered women: The effects of domestic violence on women and their children. Journal of Family Violence, 16(2), 171-192.

Levendosky, A. A., Leahy, K. L., Bogat, G. A., Davidson, W. S., \& von Eye, A. (2006). Domestic violence, maternal parenting, maternal mental health, and infant externalizing behavior. Journal of Family Psychology, 20(4), 544-552.

Levendosky, A. A., Lynch, S. M., \& Graham-Bermann, S. A. (2000). Mother's perceptions of the impact of woman abuse on their parenting. Violence against Women, 6(3), 247-271.

Lieberman, A. F., Ghosh Ippen, C., \& Van Horn, P. (2006). Child-parent psychotherapy: 6-month followup of a randomized controlled trial. Journal of the American Academy of Child and Adolescent Psychiatry, 45, 913-918.

Lieberman, A. F., \& Van Horn, P. (2005). Don't hit my mommy: A manual for child-parent psychotherapy with young witnesses of family violence. Zero to Three Press.

Lieberman, A. F., Van Horn, P., \& Ghosh Ippen, C. (2005). Toward evidence-based treatment: Child-Parent Psychotherapy with preschoolers exposed to marital violence. Journal of the American Academy of Child and Adolescent Psychiatry, 44, 1241-1248.

Lieberman, A. F., Weston, D. R., \& Pawl, J. H. (1991). Preventive intervention and outcome with anxiously attached dyads. Child Development, 62(1), 199-209.

Löwe, B., Wahl, I., Rose, M., Spitzer, C., Glaesmer, H., Wingenfeld, K., \& Brähler, E. (2010). A 4-item measure of depression and anxiety: Validation and standardization of the Patient Health Questionnaire-4 (PHQ-4) in the general population. Journal of Affective Disorders, 122(102), 86-95.

MacMillan, H. L., Wathen, C. N., Barlow, J., Fergusson, D. M., Leventhal, J. M., \& Taussig, H. N. (2009). Interventions to prevent child maltreatment and associated impairment. The Lancet, 373(9659), 250-266.

Madigan, S., Wade, M., Plamondon, A., Maguire, J. L., \& Jenkins, J. M. (2017). Maternal adverse childhood experience and infant health: Biomedical and psychosocial risks as intermediary mechanisms. The Journal of Pediatrics, 187, 282-289. 
Malone, J. C., Levendosky, A. A., Dayton, C. J., \& Bogat, G. A. (2010). Understanding the "ghosts in the nursery" of pregnant women experiencing domestic violence: Prenatal maternal representations and histories of childhood maltreatment. Infant Mental Health Journal, 31(4), 432-454.

Manning, L. G., Davies, P. T., \& Cicchetti, D. (2014). Interparental violence and childhood adjustment: How and why maternal sensitivity is a protective factor. Child Development, 85(6), 2263-2278.

Martinez-Torteya, C., Bogat, G. A., von Eye, A., \& Levendosky, A. A. (2009). Resilience among children exposed to domestic violence: The role of risk and protective factors. Child Development, 80(2), 562-577.

Miccio, K. (1995). In the name of mothers and children: Deconstructing the myth of the passive battered mother and the "protected child" in child neglect proceedings. Albany Law Review, 58(4), 1087-1107.

Miller, E., Decker, M. R., McCauley, H. L., Tancredi, D. J., Levenson, R. R., Waldman, J., \& Silverman, J. G. (2010). Pregnancy coercion, intimate partner violence, and unintended pregnancy. Contraception, 81(4), 316-322.

National Scientific Council on the Developing Child. (2012). The science of neglect: The persistent absence of responsive care disrupts the developing brain: Working paper 12. Retrieved from https://developing child.harvard.edu/resources/the-science-of-neglect-the-persistent-absence-of-responsive-care-disruptsthe-developing-brain/

Neff, K. D. (2003). The development and validation of a scale to measure self-compassion. Self and Identity, 2(3), 223-250.

Nixon, K. L., Bonnycastle, C., \& Ens, S. (2017a). Challenging the notion of failure to protect: Exploring the protective strategies of abused mothers living in urban and remote communities and implications for practice. Child Abuse Review, 26(1), 63-74. https://doi.org/10.1002/car.2417

Nixon, K. L., Tutty, L. M., Radtke, H. L., Ateah, C. A., \& Ursel, E. J. (2017b). Protective strategies of mothers abused by intimate partners: Rethinking the deficit model. Violence against Women, 23(11), 1271-1292.

Osofsky, J. D. (1995). The effects of exposure to violence on young children. American Psychologist, 50(9), 782-788.

Osofsky, J. D. (1999). The impact of violence on children. The Future of Children, 9(3), 33-49.

Paolozza, C., Packard, B., \& Kulkarni, C. (2017). A call to action on behalf of maltreated infants and toddlers in Canada. Retrieved from Toronto, ON: https://www.imhpromotion.ca/Resources/A-Call-to-Actio n2019_Web.aspx

Patteson, D. M., \& Barnard, K. E. (1990). Parenting of low birth weight infants: A review of issues and interventions. Infant Mental Health Journal, 11(1), 37-56.

Phua, D. Y., Kee, M. Z. L., \& Meaney, M. J. (2020). Positive maternal mental health, parenting, and child development. Biol Psychiatry, 87(4), 328-337. https://doi.org/10.1016/j.biopsych.2019.09.028

Pinto, R. J., Correia-Santos, P., Levendosky, A. A., \& Jongenelen, I. (2019). Psychological distress and posttraumatic stress symptoms: The role of maternal satisfaction, parenting stress, and social support among mothers and children exposed to intimate partner violence. Journal of Interpersonal Violence, 34(19), 4114-4136.

Poole, A., Beran, T., \& Thurston, W. E. (2008). Direct and indirect services for children in domestic violence shelters. Journal of Family Violence, 23(8), 679-868.

Raes, F., Pommier, E., Neff, K. D., \& Van Gucht, D. (2011). Construction and factorial validation of a short form of the self-compassion scale. Clinical Psychology and Psychotherapy, 18(3), 250-255.

Rigterink, T., Fainsilber Katz, L., \& Hessler, D. M. (2010). Domestic violence and longitudinal associations with children's physiological regulation abilities. Journal of Interpersonal Violence, 25(9), 1669-1683.

Schechter, D. S., Coates, S. W., Kaminer, T., Coots, T., Zeanah, C. H., Davies, M., \& Myers, M. M. (2008). Distorted maternal mental representations and atypical behavior in a clinical sample of violence-exposed mothers and their toddlers. Journal of Trauma and Dissociation, 9(2), 123-147.

Schechter, D. S., Willheim, E., McCaw, J., Turner, J. B., Myers, M. M., \& Zeanah, C. H. (2011). The relationship of violent fathers, posttraumatically stressed mothers and symptomatic children in a preschool-age inner-city pediatrics clinic sample. Journal of Interpersonal Violence, 26(18), 3699-3719.

Schechter, S., \& Edleson, J. L. (1994). In the best interest of women and children: A call for collaboration between child welfare and domestic violence constitutencies. Retrieved from http://www.mincava.umn. edu/documents/wingsp/wingsp.html

Shepard, M., \& Raschick, M. (1999). How child welfare workers assess and intervene around issues of domestic violence. Child Maltreatment, 4(2), 148-156.

Shipman, K. L., Rossman, B. B. R., \& West, J. C. (1999). Co-occurrence of spousal violence and child abuse: Conceptual implications. Child Maltreatment, 4(2), 93-102. 
Stanley, N. (1997). Domestic violence and child abuse: Developing social work practice. Child and Family Social Work, 2, 135-145.

Swift, K. J. (1995). Manufacturing 'bad mothers': A critical perspective on child neglect. University of Toronto Press.

Tesh, M., Learman, J., \& Pulliam, R. M. (2015). Mindful self-compassion strategies for survivors of intimate partner abuse. Mindfulness, 6(2), 192-201.

Thayer, J. F., Hansen, A. L., Saus-Rose, E., \& Johnsen, B. H. (2009). Heart rate variability, prefrontal neural function, and cognitive performance: The neurovisceral integration perspective on self-regulation, adaptation, and health. Annals of Behavioral Medicine, 37(2), 141-153.

Toth, S. L., Rogosch, F. A., Manly, J. T., \& Cicchetti, D. (2006). The efficacy of toddler-parent psychotherapy to reorganize attachment in the offspring of mothers with major depressive disorder: A randomized preventive trial. Journal of Consulting and Clinical Psychology, 74(6), 1006-1016.

Trocmé, N., Fallon, B., MacLaurin, B., Sinha, V., Black, T., Fast, E., \& Helie, S. (2010). Canadian Incidence Study of Reported Child Abuse and Neglect - 2008: Major findings. Ottawa, ON: Public Health Agency of Canada. Retrieved from https://cwrp.ca/sites/default/files/publications/en/CIS-2008-rprt-eng.pdf

Tronick, E. (2017). The caregiver-infant dyad as a buffer or transducer of resource enhancing or depleting factors that shape psychobiological development. Australian \& New Zealand Journal of Family Therapy, 38, 561-572. https://doi.org/10.1002/anzf.1274

Tsavoussis, A., Stawicki, S. P. A., Stoicea, N., \& Papdimos, T. J. (2014). Child-witnessed domestic violence and its adverse effects on brain development: A call for societal self-examination and awareness. Frontiers in Public Health, 2(178). https://doi.org/10.3389/fpubh.2014.00178

Urquhart, C., \& Jasiura, F. (2013). Trauma-informed practice guide. Retrieved from http://bccewh.bc.ca/wpcontent/uploads/2012/05/2013_TIP-Guide.pdf

Weaver, C. M., Shaw, D. S., Dishion, T. J., \& Wilson, M. N. (2008). Parenting self-efficacy and problem behavior in children at high risk for early conduct problems: The mediating role of maternal depression. Infant Behaviour and Development, 31(4), 595-605.

Whitney, P., \& Davis, L. (1999). Child abuse and domestic violence in Massachusetts: Can practice be integrated in a public child welfare setting? Child Maltreatment, 4(2), 158-166.

Wilson, C. (1998). Are battered women responsible for protection of their children in domestic violence cases? Journal of Interpersonal Violence, 13(2), 289-293.

Wittkowski, A., Dowling, H., \& Smith, D. M. (2016). Does engaging in a group-based intervention increase parental self-efficacy in parents of preschool children? A systematic review of the current literature. Journal of Child \& Family Studies, 25, 3173-3191.

Wolfe, D. A., Crooks, C. V., Lee, V., McIntyre-Smith, A., \& Jaffe, P. G. (2003). The effects of children's exposure to domestic violence: A meta-analysis and critique. Clinical Child and Family Psychology Review, 6(3), 171-187.

Sura-Liddell, L., \& Jenney, A. (2016). Mothers in Mind: A Trauma-Informed Mother-Child Group Intervention Program Session Guide. Child Development Institute. Toronto, Ontario, Canada.

Publisher's note Springer Nature remains neutral with regard to jurisdictional claims in published maps and institutional affiliations.

\section{Authors and Affiliations}

\section{Angelique Jenney ${ }^{1,2}\left(\mathbb{D} \cdot\right.$ Katreena Scott $^{3} \cdot$ Michael Wall $^{4,5}$}

1 Faculty of Social Work, University of Calgary, Toronto, Canada

2 Safe \& Understood Project, Child Development Institute, Toronto, Canada

3 Western University and University of Toronto, Toronto, ON, Canada

4 Child Development Institute, Toronto, Canada

5 University of Toronto, Toronto, ON, Canada 